\title{
Adverse drug reactions in hospitalized patients in a tertiary care teaching hospital: analysis of the reported cases
}

\author{
Althab Begum M., Satyajit Mohapatra*, R. Jamuna Rani
}

Department of Pharmacology, SRM Medical College Hospital and Research Center, SRM University, Chennai, Tamil Nadu, India, 603203

Received: 04 May 2018 Accepted: 26 May 2018

*Correspondence to: Dr. Satyajit Mohapatra, Email: satyajitmp@gmail.com

Copyright: (C) the author(s), publisher and licensee Medip Academy. This is an openaccess article distributed under the terms of the Creative Commons Attribution NonCommercial License, which permits unrestricted noncommercial use, distribution, and reproduction in any medium, provided the original work is properly cited.

\begin{abstract}
Background: Adverse Drug Reactions (ADR's) contributes to the burden of drug-related morbidity and mortality. ADRs are seen frequently in hospitals due to a variety of factors like complexity of diseases, drug interactions, polypharmacy, and possible negligence. The purpose of the study was to identify and assess ADR in various departments of a tertiary care teaching hospital.

Methods: A prospective spontaneous reporting was carried out in a tertiary care teaching hospital during a period of four months from November 2016 to February 2017. All suspected spontaneous ADRs were assessed and the information was collected and analyzed by the pharmacologists for causality assessment using the Naranjo's causality assessment scale.

Results: A total of 30 ADRs were reported with female preponderance (70\%). Majority of ADRs were from General Medicine and Oncology departments. The most affected organ systems were skin (80\%) followed by the gastrointestinal system $(13.3 \%)$. The most frequent drugs causing ADRs were antibiotics $(56.3 \%)$ in which type B reactions were more compared to type A and followed by anticancer drugs (10\%). The severity assessment showed that most of them were mild reactions $(76.6 \%)$. Causality assessment revealed that $90 \%$ of the reactions were probable, $10 \%$ were possible and no reactions were unlikely.

Conclusions: The study accomplished that ADRs are widespread and a few of them raised the healthcare expenditure due to increased hospital stay. The reporting of the ADRs to regional Pharmacovigilance centers should be encouraged to ensure drug safety.
\end{abstract}

Keywords: Adverse drug reactions, Drug safety, Pharmacovigilance

\section{INTRODUCTION}

As per the World Health Organization's (WHO) definition, the ADR is "response to a drug, which is noxious and unintended, and which occurs at doses normally used in man for prophylaxis, diagnosis or therapy of disease, or for the modification of physiological function. ${ }^{1}$ ADR is a global problem and a major concern in patient safety and clinical practice and patients are treated with multiple drugs where ADRs are inevitable. The potential consequences of ADR are it affects patient's quality of life, it imposes significant economic burden to the patients and make them to lose confidence in their treating patients. If we believe that the first principle in treating patients is 'primum non nocere' i.e., 'above all do no harm' we should be aware of the possibility of ADRs.

The aim of this study is to establish a causal relation between the drug and adverse events. The causality assessment system proposed by the World Health Organization Collaborating Centre for International Drug Monitoring, the Uppsala Monitoring Centre (WHOUMC), and the Naranjo Probability Scale are the generally accepted and most extensively used methods for causality assessment in clinical practice. ${ }^{2}$ Early recognition, evaluation and monitoring of ADR are essential to improve public health. In the United States, it has been 
reported that $\mathrm{ADRs}$ due to over the counter and prescription drugs from 1966 to 1996 affected $6.7 \%$ of patients with $3.2 \%$ death. ${ }^{3}$ While similar figures are not available for India, it is logical to assume that the figures would be much higher considering high levels of unmonitored and indiscriminate drug use widespread in the country. ${ }^{4}$ ADR monitoring and reporting activity is in its early years in this country. India is a developing country with a large drug utilizing population. It is the fourth largest producer of pharmaceuticals in the world with over 6000 licensed drug manufacturers and around 60,000 branded formulations. It is also emerging as a clinical trial focus exposing greater population to new drugs.

It is critical to identify ADRs at the earliest and to prevent them if possible, to ensure the welfare of the patient at a reasonable expenditure. Pharmacovigilance plays an important role in judicial use of medicines. ${ }^{5}$ It is estimated that only $5 \%$ of ADRs are reported ${ }^{6,7}$ For effective patient care, there is an urgent need to develop better preventive strategies and reporting of ADR by every health care provider to be made mandatory.

The Central Drugs Standard Control Organisation (CDSCO), New Delhi, under the guidance of Ministry of Health and Family Welfare, Government of India has initiated a countrywide pharmacovigilance programme (PvPI), with the All India Institute of Medical Sciences (AIIMS), New Delhi as the National Coordinating Centre for monitoring ADRs in the nation. Our hospital is one of the centres for monitoring and reporting ADRs through this programme.

PvPI increased the ADRs monitoring centers from 90 to 150 including the private hospitals, which led to increasing in ADR reporting. India became the first country in reporting the Individual Case Safety Reports of more than one lakh to Vigiflow, Uppsala Monitoring Centre. It has to be made mandatory for all health-care providers such as physicians, dentists, nurses, pharmacists to report ADRs as part of their professional responsibility, even if they are doubtful about the specific relationship with the given medication. One of the most important ways to prevent adverse drug events is to share information since all medication errors are preventable.

\section{METHODS}

After Institutional Ethical Committee approval, hospitalization due to adverse drug reactions from various departments in this tertiary care hospital was analyzed. A prospective study was conducted from November 2016 to February 2017, for a period of four months. ADR details were obtained after getting oral informed consent from the concerned patients. The data for the study were taken from case sheets, investigation reports, personal interviews with clinicians, and personal interviews with patient or patient's attendant, past history of medications and reports of Medical and surgical interventions. The causality assessment of the reported ADRs was done using the
Naranjo causality assessment scale into definite, probable, or possible. ${ }^{8}$ After calculating the total score, based on the score they were grouped as certain if score $>9$, probable if score is between 5-8 and possible if score is between 1-4. The modified Hartwig and Siegel scale defines the severity of ADR as mild, moderate or severe according to factors like necessities for change in treatment, length of hospital stay, and the disability produced by the ADR. ${ }^{9}$

\section{RESULTS}

Descriptive analysis of the ADR data collected is done by Microsoft Excel software and expressed as percentage comparison. The number of hospital admissions due to Adverse Drug Reaction was 30. Of these 09 (30\%) were male and $21(70 \%)$ were female. The more number of ADR's were reported 36-59 years 14 (46.6\%) patients, and least were in elderly age group comprised of 4 patients (13.2\%) (Table1). According to the Naranjo's causality assessment scale, $6.66 \%$ of the ADRs were certain, $86.6 \%$ probable and $6.66 \%$ were possible as shown in Figure 1.

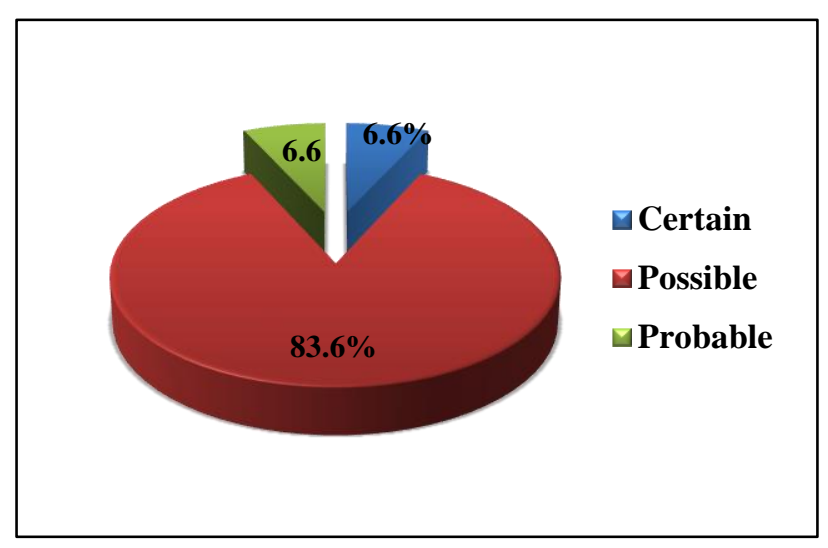

Figure 1: Causality assessment of the total ADRs reported using Naranjo's scale.

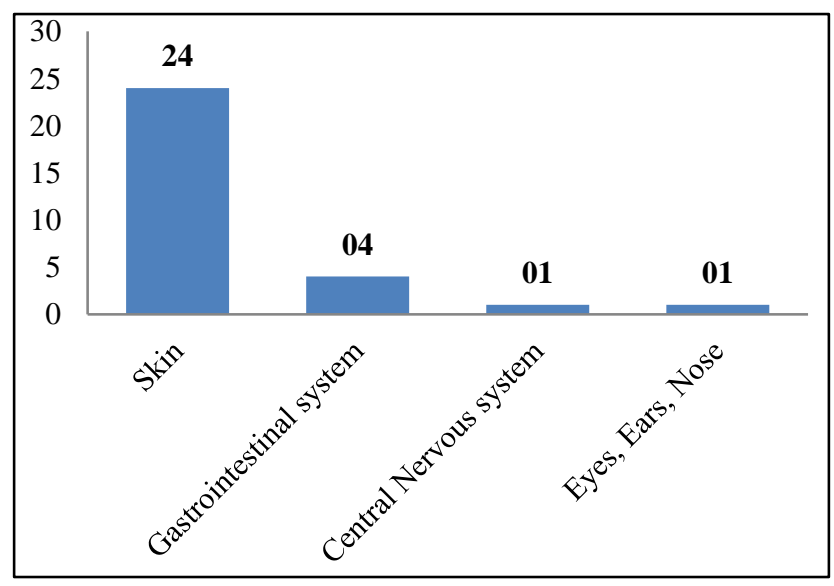

Figure 2: Different organ system affected due to ADRs and the total number of ADRs involved the corresponding organ system.

Out of 30 ADR's the major preponderance of drugs were Antimicrobial agents, $16(53.3 \%)$ and anti cancer drugs 
(20\%). Among them, Ciprofloxacin was the highest with $04(13.3 \%)$, followed by Ceftriaxone $03(10 \%)$ as shown in Table 2.

Table 1: Age and gender distribution in reported ADR's.

\begin{tabular}{|lll|}
\hline Age distribution & Male & Female \\
\hline$<35$ years & $5(16.6 \%)$ & $7(23.3 \%)$ \\
\hline 36-59 years & $2(6.6 \%)$ & $12(40 \%)$ \\
\hline 60 years & $2(6.6 \%)$ & $2(6.6 \%)$ \\
\hline Total & $9(30 \%)$ & $21(70 \%)$ \\
\hline
\end{tabular}

Table 2: Drugs and the routes of administration involved in reported ADRs.

\begin{tabular}{|c|c|c|}
\hline Drugs & Route & No. of ADRs \\
\hline Ciprofloxacin & IV & $04(13.3 \%)$ \\
\hline Ceftriaxone & IV & $03(10 \%)$ \\
\hline Sulfonamide & $\mathrm{P} / \mathrm{o}$ & $02(6.6 \%)$ \\
\hline Oxaliplatin & IV & $02(6.6 \%)$ \\
\hline Fluconazole & $\mathrm{P} / \mathrm{o}$ & $02(6.6 \%)$ \\
\hline Ranitidine & IV & $02(6.6 \%)$ \\
\hline Renerve Plus & $\mathrm{P} / \mathrm{o}$ & $02(6.6 \%)$ \\
\hline Amoxicillin & IV & $01(3.3 \%)$ \\
\hline Cefixime & IV & $01(3.3 \%)$ \\
\hline Paclitaxel & IV & $01(3.3 \%)$ \\
\hline Cefotaxime & IV & $01(3.3 \%)$ \\
\hline Sulfasalazine & $\mathrm{P} / \mathrm{o}$ & $01(3.3 \%)$ \\
\hline Paracetamol & IV & $01(3.3 \%)$ \\
\hline $\begin{array}{l}\text { Cefaperazone and } \\
\text { Sulbactam }\end{array}$ & IV & $01(3.3 \%)$ \\
\hline Ringer Lactate & IV & $01(3.3 \%)$ \\
\hline Vancomycin & IV & $01(3.3 \%)$ \\
\hline Timolol Eye Drops & $\mathrm{E} / \mathrm{d}$ & $01(3.3 \%)$ \\
\hline Cisplatin & IV & $01(3.3 \%)$ \\
\hline Benzocaine & $\mathrm{E} / \mathrm{A}$ & $01(3.3 \%)$ \\
\hline Sulfadoxime & $\mathrm{P} / \mathrm{o}$ & $01(3.3 \%)$ \\
\hline Total & & $\mathrm{N}=30$ \\
\hline
\end{tabular}

IV: Intravenous, P/o- per oral, E/d- Eye drops, E/A- -External Application

Table 3: ADRs reported from various departments.

\begin{tabular}{|ll|}
\hline $\begin{array}{l}\text { Department wise ADR } \\
\text { reported }\end{array}$ & No. of ADR's (\%) \\
\hline Medicine & 23.3 \\
\hline Oncology & 20 \\
\hline Surgery & 13.3 \\
\hline Obstetrics and Gynaecology & 10 \\
\hline Dermatology & 10 \\
\hline Nephrology & 10 \\
\hline Orthopaedics & 6.6 \\
\hline Ophthalmology & 3.3 \\
\hline Cardiothoracic & 3.3 \\
\hline
\end{tabular}

The most number of ADR's were reported in the department of General Medicine (23.3\%), Oncology $(20 \%)$ and General Surgery $(13.3 \%)$ as mentioned in Table 3. Itching was the most common ADR reported in 09 patients $(30 \%)$ followed by swelling $06(20 \%)$ and rashes $06(20 \%)$ (Table 4$)$. The most commonly affected system was found to be the skin $24(80 \%)$, followed by Gastrointestinal system $4(13.3 \%)$ as in Figure 2.

Table 4: Different types of Adverse drug reactions.

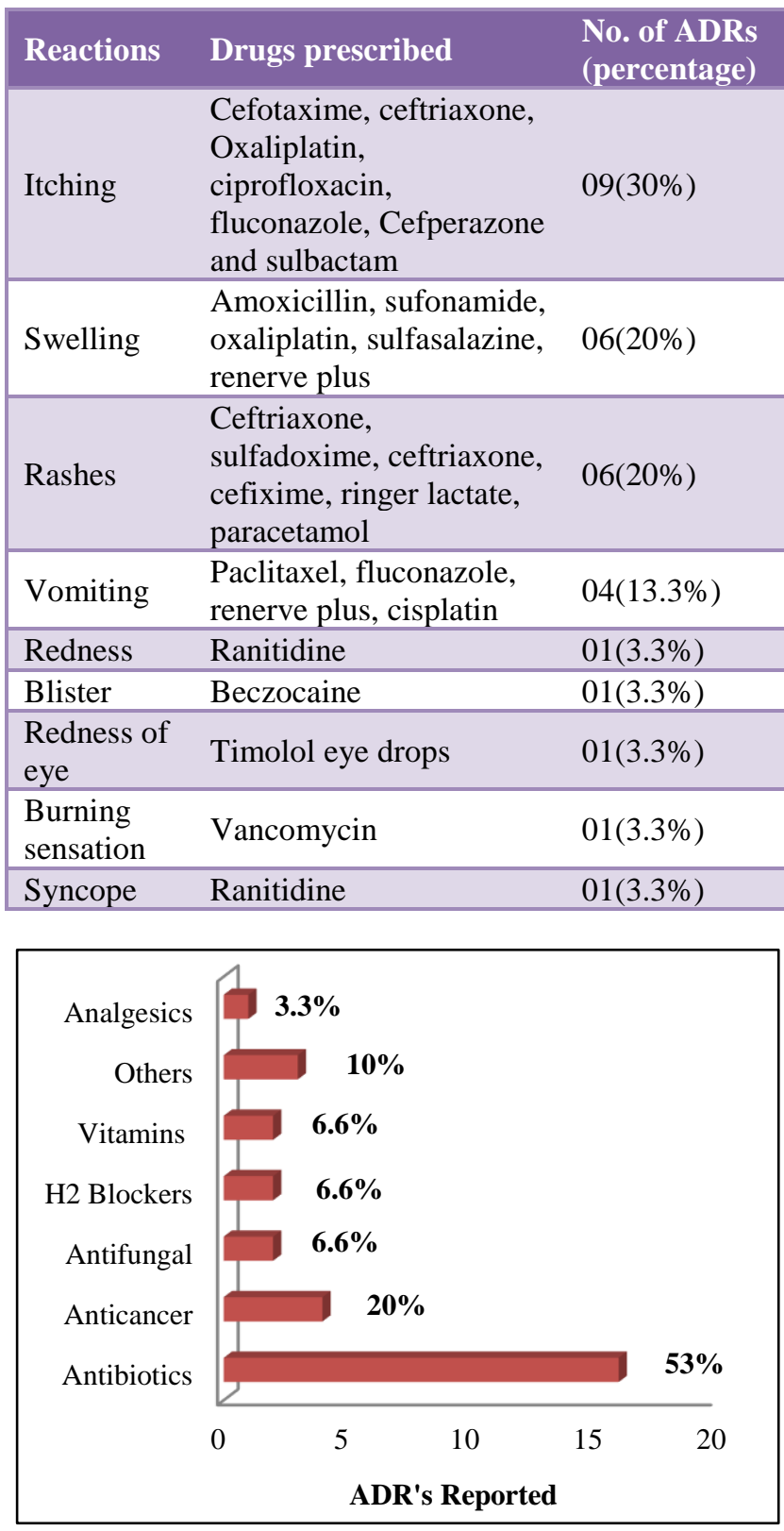

Figure 3: Different group of drugs and the total number of reactions reported for each group in percentage.

\section{DISCUSSION}

The data are limited for the spontaneous adverse drug reaction (ADR) reporting system in India and its 
comparison in terms of causative drugs, seriousness of the reactions, and the different organ system involved in the ADRs. Spontaneous ADR reporting by health professionals and individuals is practiced in many countries, but in India there is lack of spontaneous reporting. The Pharmacovigilance program of India has taken an initiative in reporting of ADRs from various ADR monitoring center routinely.

ADR Monitoring Committee that is charged with the responsibility of reviewing all suspected cases of ADRs and forwarding the list of confirmed cases to the National coordinating Centre (NCC). We have analysed the ADRs reported from the ADR monitoring center of the medical college.

Majority of ADRs (86.6\%) were seen in adult age group which was comparable with the previous study by Sharma et al. where it was $50.4 \% .^{10}$ The most frequent ADRs were due to the antibiotics which could be associated with increased frequency of prescription of antibiotics. The number of ADRs were high in General Medicine and General Surgery departments due to amplified use of antibiotics in these departments for the treatment and prophylaxis of various diseases and also since the patients admitted were with multiple co morbidities requiring polypharmacy.

Classification of reported ADR's revealed Type B predominance. This result is in line with the study by Suthar and Desai but on the contrary, studies conducted by Oshikoya et al, and Stavreva et al, showed a preponderance of Type A reactions. ${ }^{11-13}$

On analysing the fate of the suspected drugs, it was found that the drug was withdrawn in most of the cases and the dose was reduced in some while no change was made in others considering the risk benefit ratio in particular patients. Majority of the patients recovered completely from the ADR since most of the reactions were mild according to the modified Hartwig and Siegel scale. However, the study carried out by Shamna et al, reported that moderate reactions were more followed by mild and severe ones. The causality assessment of the reported ADRs according to the Naranjo scale revealed that no reactions were unlikely and most of them were probable with a lesser number of possible and definite ADRs. This data is in correlation with the study of Jimmy Jose et al. ${ }^{14}$

\section{CONCLUSION}

This study creates awareness to the healthcare professionals and patients on the significance of scrutinizing and reporting the adverse drug reactions. In order to ensure the safety of the drugs the healthcare system should promote the spontaneous reporting and documenting of Adverse Drug Reactions.

Funding: No funding sources

Conflict of interest: None declared
Ethical approval: The study was approved by the Institutional Ethics Committee

\section{REFERENCES}

1. Geneva: World Health Organization, World Health Organization. Safety of medicines - A guide to detecting and reporting adverse drug reactions - Why health professionals need to take actions, Accessed on 2nd September 2015. Available at: http://apps.who.int/medicinedocs/en/d/Jh2992e/ 6.html.

2. Naranjo CA, Busto U, Sellers EM, Sandor P, Ruiz I, Roberts EA. A method for estimating the probability of adverse drug reactions. Clin Pharmacol Ther. 1981:30:239-45. [PubMed].

3. Lazarou J, Pomeranz BH, Corey PN. Incidence of adverse drug reactions in hospitalized patients: a metaanalysis of prospective studies. JAMA. 1998;279(15):1200-5.

4. Sriram S, Ghasemi A, Ramasamy R, Devi M, Balasubramanian R, Ravi TK. Prevalence of adverse drug reactions at a private tertiary care hospital in south India. Journal of Research in Medical Science: The Offi $\mathrm{J}$ of Isfahan Uni of Med Scienc. 2011;16(1):16-25.

5. WHO and Uppsala Monitoring Centre The Importance of Pharmacovigilance. Geneva: WHO and Uppsala Monitoring Centre; 2002. Available at: http://www.who-umc.org.

6. Wood AJ, Stein CM, Woosley RL. Making medicines safer-the need for an independent drug safety board. N Engl J Med. 1998;339:1851-4.

7. Aziz Z, Siang TC, Badarudin NS. Reporting of adverse drug reactions: predictors of under-reporting in Malaysia. Pharmacoepidemiol Drug Saf. 2007;16(2):223-8.

8. Naranjo CA, Busto U, Sellers EM, Sandor P, Ruiz I, Roberts EA. Method for estimating the probability of adverse drug reactions. Clin Pharmacol Ther. 1981;80:289-95.

9. Hartwig SC, Siegel J, Schneider PJ. Preventability and severity assessment in reporting adverse drug reactions. Am J Hosp Pharm. 1992;49:2229-32.

10. Sharma VK, Sethuraman G, Kumar B. Cutaneous adverse drug reactions: Clinical pattern and causative agents - a 6 year series from Chandigarh, India. J Postgrad Med. 2001;47(2):95-9.

11. Suthar JV, Desai SV. A study of adverse cutaneous drug reactions in outdoor patients attending to skin and V.D. Department of Shree Krishna Hospital, Karamsad. Int $\mathrm{J}$ Res Pharm Biomed Sci. 2011;2(1):274-9.

12. Oshikoya KA, Njokanma OF, Chukwara HA, Ojo IO. Adverse drug reactions in Nigerian children. Paediatr. Perinat. Drug Ther. 2007;8:81-8.

13. Stavreva G, Pendicheva D, Pandurska A, Marev R. Detection of adverse drug reactions to antimicrobial drugs in hospitalized patients. Trakia J Sci. 2008;6(1):7-9. 
14. Jose J, Rao Padma GM, Jimmy B. Adverse drug reactions to fluoroquinolone antibiotics - Analysis of reports received in a tertiary care hospital. Int J Risk Saf Med. 2008;20:169-80.
Cite this article as: Begum AM, Mohapatra S, Rani RJ. Adverse drug reactions in hospitalized patients in a tertiary care teaching hospital: analysis of the reported cases. Int J Basic Clin Pharmacol 2018;7:1377-81. 